\title{
Copulation pheromone in the crab Telmessus cheiragonus (Brachyura: Decapoda)
}

\author{
Michiya Kamio, Shigeki Matsunaga, Nobuhiro Fusetani*
}

Laboratory of Aquatic Natural Products Chemistry, Graduate School of Agricultural and Life Sciences, University of Tokyo, 1-1-1 Yayoi, Bunkyo-ku, Tokyo 113-8657, Japan

\begin{abstract}
Animals employ multi-step mate recognition processes to mate with their proper partners, for a given mating season. The signals used in mate recognition in Crustacea are fairly well studied, but these studies have so far focused on the signals used in precopulatory (or courtship) behavior. Signals that mediate copulation have never been experimentally demonstrated. Here, we report the presence of a copulation pheromone in the crab Telmessus cheiragonus which was previously undescribed in brachyuran Crustacea. This pheromone is released from postmolt females for more than $21 \mathrm{~d}$ after molting and evokes copulation behavior in male crabs. The postmolt female urine that contains precopulatory mate-guarding-inducing pheromone did not induce copulatory behavior in male crabs. Postmolt females that were prevented from releasing urine still elicited copulation behavior in males, thereby indicating that the pheromone is different from a pheromone that elicits precopulatory guarding in males. The copulation pheromone is a water-borne pheromone with a molecular weight of less than $1 \mathrm{kDa}$. T. cheiragonus employs 1 pheromone that elicits precopulatory guarding and another pheromone that elicits copulation. This strategy ensures mating between proper partners.
\end{abstract}

KEY WORDS: Copulation pheromone $\cdot$ Crustacea $\cdot$ Crab $\cdot$ Mate recognition $\cdot$ Telmessus cheiragonus Resale or republication not permitted without written consent of the publisher

\section{INTRODUCTION}

Sexually reproducing animals have to have reliable mate recognition processes to ensure successful fertilization. Distinct signals elicit distinct behaviors involved in the multiple steps of mate recognition sequences in golden hamsters (Agosta 1992), coleopteran insects (Fauziah et al. 1992), ticks (Soneshine 1985) and nereidid polychaetes (Hardege 1999), where the first mate recognition and copulation (or synchronized gamete release) are elicited by different chemical stimuli.

Among brachyuran crustaceans, the signals and responses in mate recognition have been well studied. Terrestrial species employ visual and acoustic signals, while many aquatic species use chemical signals in attraction and localization of their partners (Salmon

*Corresponding author. E-mail: anobu@mail.ecc.u-tokyo.ac.jp
1983). There are 2 basic types of mating patterns in brachyuran crabs that are referred to as hard-female mating (HFM) and soft-female mating (SFM), the former is mainly terrestrial and the latter is mainly aquatic (Hartnoll 1969). In HFM type crabs, copulation occurs when the carapace of a female is fully hardened, whereas in SFM type crabs, copulation occurs after a female molt when the carapace is soft. SFM type female crabs release a pheromone from the antennal gland openings and other release sites that elicits precopulatory behaviors in males (Dunham 1978, Bamber \& Naylor 1997). The precopulatory behaviors such as searching, copulatory dance and grasping, have been described for the portunid crabs Portunus sanguinolentus (Ryan 1966), Callinectes sapidus (Gleeson 1980) and Carcinus maenas (Eales 1974, Bamber \& Naylor 1996a), and an atelecyclid crab, Telmessus cheiragonus (Kamio et al. 2000). After meeting, the male grasps and carries the female until she molts. Copulation takes place shortly after ecdysis (Hartnoll 
1969). The roles of vision and tactile stimuli in precopulatory mate recognition processes have also been described in some fully aquatic brachyurans (Gleeson 1980, Bamber \& Naylor 1996a). However, signals that mediate copulation (insertion of gonopods and ejaculation) have never been experimentally demonstrated. In other words, there is no description about how the male recognizes the molted female.

The helmet crab Telmessus cheiragonus is a fully aquatic SFM type crab. Molting of sexually competent females takes place once a year and is linked to copulation (Nagao 1999). In the mating season, a male grasps a premolt female and carries her until she molts (precopulatory guard). Immediately afterwards, copulation takes place and this is followed by a short postcopulatory guard (Asai 1996). Thus, the mating behaviors of $T$. cheiragonus are typical for the SFM type aquatic brachyuran crabs, which can be divided into 2 successive stages: Stage 1, mate location and initiation of precopulatory guarding, and Stage 2, molting of female and copulation. In Stage 1, a water-borne pheromone contained in urine released from premolt female evokes the grasping behavior in males (Kamio et al. 2000) as reported in portunid crabs (Ryan 1966, Eales 1974, Gleeson 1980). In Stage 2, the male perceives the ecdysing and holds the female in the copulation position, after which the male inserts his gonopods into the female gonopores and transfer of sperm takes place. At the end of the copulation, the male deposits plugs into the female gonopores (Fig. 1A). Currently, however, no information of any stimulus release from postmolt females that elicits male copulation behavior is available.

The present study was conducted to determine the nature of the stimuli that elicits copulatory behavior of Telmessus cheiragonus males. The stimulus that evokes the precopulatory behaviors was observed to be a water-borne chemical signal released from the premolt female. We examined the chemical signal released from the postmolt female which triggers cop-

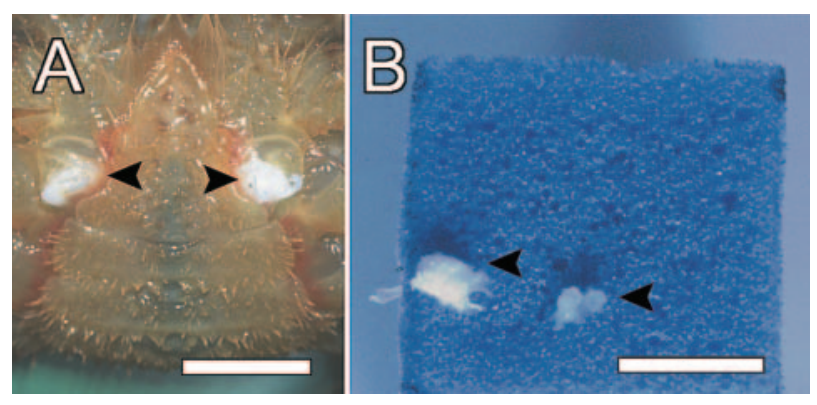

Fig. 1. Telmessus cheiragonus. Sperm plugs on a postmolt female and a urethane sponge. (A) Ventral view of copulated female (scale bar $=1 \mathrm{~cm}$ ). (B) Urethane sponge possessing sperm plug (scale bar $=1 \mathrm{~cm}$ ). Arrowheads show sperm plugs ulation. Aquarium waters of pre- and postmolt females were assessed for their chemical stimuli. The release duration of the pheromone was examined. Investigations were undertaken to assess antennal gland openings, body surface, gonopore, anus, and inside of abdominal flap as potential release sites of copulation pheromone. Finally, the molecular size of the pheromone was estimated by ultrafiltration.

\section{MATERIALS AND METHODS}

Crab samples. Pre-copula pairs and solo males were collected from pier walls in Usujiri, Hokkaido (41 $57^{\circ} \mathrm{N}$, $\left.140^{\circ} 58^{\prime} \mathrm{E}\right)$ during the mating season between April and June from 1999 to 2001. Both paired males which had been separated from their partner females, and solo males, were maintained at $10.5 \pm 1^{\circ} \mathrm{C}$ in an aquarium with a recirculating seawater system (32.2\%) for a minimum of $2 \mathrm{~d}$ prior to experiments under natural photoperiods. Females were housed in a separate flowthrough seawater system (32.2\%) at ambient temperature. Males (46.5 to $68.0 \mathrm{~mm}$ carapace length [CL]), premolt females (39.2 to $49.0 \mathrm{~mm} \mathrm{CL}$ ), and postmolt females (26.2 to $53.2 \mathrm{~mm} \mathrm{CL}$ ) were used for experiments. Individual males and females were used only once for behavioral experiments.

Sponge assay. To examine the chemical signals released from pre- and postmolt females, behavioral tests of male crabs using artificial sponges as female dummies were carried out by the modified method reported by Kamio et al. (2000). The sponges were washed with seawater before use. Male crabs maintained in an aquarium with a recirculating seawater system at $10^{\circ} \mathrm{C}$ were randomly selected and transferred into still water test aquaria $(31.5 \times 18.5 \times 24.4 \mathrm{~cm})$ and acclimated individually at $15^{\circ} \mathrm{C}$ for $4 \mathrm{~h}$. The sponges $(2.5 \times 2.5 \times 4 \mathrm{~cm})$ were placed with tweezers in front of males in contact with the chelae. Then behaviors of the male crab was observed for $1 \mathrm{~h}$. Two particular types of behavior were recorded as unmistakable and reliable criteria for sexual reaction: (1) Grasping, a behavior in which the male grasps and fumbles with the sponge to place it into the precopulatory guard position (Fig. 2A). No eating behavior is oberserved; and (2) Copulation, a behavior in which the male first shows 'grasping', and then opens his abdomen to expose the sexual appendages and moves the sponge onto the gonopods for insertion (Fig. 2B).

The behavioral responses of males were observed at night under artificial red light. Each sponge was used only once for experiments.

Detection of copulation behavior-eliciting pheromone. Types of male behavior were assessed as described above with the sponges treated as follows: 


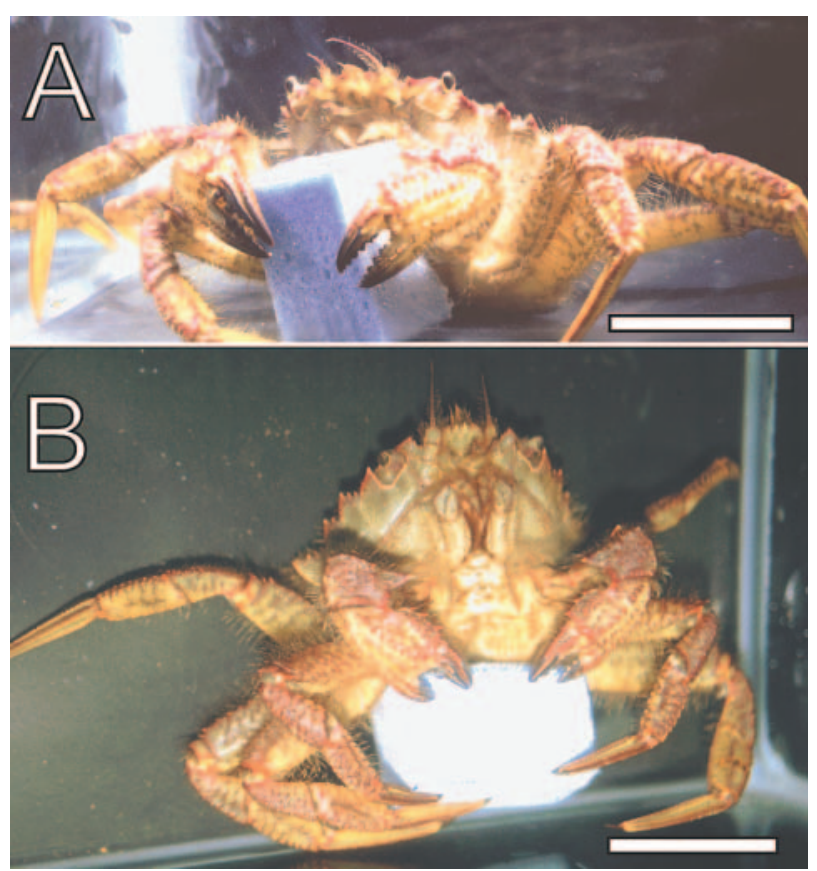

Fig. 2. Telmessus cheiragonus. Sexual behaviors of male crab towards urethane sponges containing sex pheromones. (A) Precopulatory guard behavior of the male towards a urethane sponge containing the premolt female tank water (scale bar = $4 \mathrm{~cm}$ ). (B) Copulation behavior of the male towards a urethane post-maintained sponge containing the postmolt female tank water $($ scale bar $=4 \mathrm{~cm})$

Pre-maintained: Ten urethane sponges were maintained for $20 \mathrm{~h}$ in a $5 \mathrm{l}$ tank containing 8 premolt females.

Post-maintained: Ten sponges were maintained for $20 \mathrm{~h}$ in a $5 \mathrm{l}$ tank containing 8 postmolt females that had molted 2 to $3 \mathrm{~d}$ before.

Pre-dipped: Sponges were briefly dipped in the water of the tanks described in 'Pre-maintained', and pressed and released by tweezers to exchange the water contained in them. This was done just before the assay and the sponges were immersed in the water of the male crab tanks within 1 min of this procedure.

Post-dipped: Sponges were briefly dipped in the water of the tanks described in 'Post-maintained' as described in 'Pre-dipped'.

$S W$-dipped (Control): Sponges were dipped in fresh seawater as described in 'Pre-dipped'.

Differences in male responses among each treatment group were evaluated by the Fisher exact test (Zar 1999).

Estimation of a molecular size of the copulation pheromone. The pheromone containing water was obtained as follows. Ten postmolt females were maintained in an aquarium containing $3 \mathrm{l}$ of seawater at $10^{\circ} \mathrm{C}$ for $30 \mathrm{~h}$. The aquarium water was then filtered through a glass filter, and the filtrate was subjected to membrane ultrafiltration using 10 and $1 \mathrm{kDa}$ cutoff membranes (Diaflo membranes, Amicon). The filtrates thus obtained were stored at $-20^{\circ} \mathrm{C}$ until required. The glass filter filtrate, $10 \mathrm{kDa}$ and $1 \mathrm{kDa}$ filtrates were diluted with seawater to $1 / 4$ concentration and are referred to as glass filtrate, $10 \mathrm{kDa}$ filtrate, and $1 \mathrm{kDa}$ filtrate. Thirty sponges were soaked in $600 \mathrm{ml}$ of each filtrate, while 20 sponges were soaked in $400 \mathrm{ml}$ of seawater (SW) for $1 \mathrm{~h}$ at $15^{\circ} \mathrm{C}$. These sponges were assessed by sponge assay. Differences in male responses between the treatment groups were evaluated by the Fisher exact test (Zar 1999).

Duration of the pheromone release. Duration of the release of the copulation pheromone from postmolt females was examined by the sponge assay described above. Two groups of 10 postmolt females that molted on the same day were kept separately in a flowthrough tank system at ambient temperature. Each group was transferred to a 51 still water tank into which 10 sponges were placed and maintained for $20 \mathrm{~h}$. These females were transferred to the flowthrough tank and maintained until the next experiment. The types of behavior of 10 male crabs were observed for each sponge group conditioned with the postmolt females which had molted 2, 4, 6, 9, 12, 15, 18, and $21 \mathrm{~d}$ earlier.

On Day 22 after the molt, responses of males toward the 'real' females were observed. Male crabs maintained in a flowthrough system at ambient temperature were transferred into still water test aquariums $(31.5 \times$ $18.5 \times 24.4 \mathrm{~cm}$ ) and acclimated for $1 \mathrm{~h}$ at $13^{\circ} \mathrm{C}$. Then, the females that had molted $22 \mathrm{~d}$ before were placed in the aquariums to start the trial. The interaction of the males and females was observed for $1 \mathrm{~h}$. The carapaces of the females were already fully hardened when they were used in this experiment.

Location of the release site of the copulation pheromone. To locate the releasing site of the copulation pheromone, we first compared the activity of the postmolt female urine with aquarium water conditioned with postmolt females. From the antennal gland opening of postmolt females, $200 \mathrm{ml}$ of urine were collected as described before (Kamio et al. 2000) and stored at $-20^{\circ} \mathrm{C}$ until required. For aquarium water conditioned with postmolt females, $200 \mathrm{ml}$ from 51 of aquarium water, in which 30 postmolt females ( 2 to $3 \mathrm{~d}$ postmolt) were kept for $2 \mathrm{~d}$, was collected and stored at $-20^{\circ} \mathrm{C}$ until required. The sponges were soaked in $200 \mathrm{ml}$ of the urine (postmolt urine) or $200 \mathrm{ml}$ of the aquarium water (postmolt water) for $2 \mathrm{~h}$ prior to experiments. Male responses were observed by the sponge assay described above. Differences in male responses between the 2 treatment groups were evaluated by the Fisher exact test (Zar 1999). 
The antennal gland openings of postmolt females were closed to prevent urine release, and the behavior of males toward the treated females was observed. The anntenal gland openings of 10 postmolt females that had molted 1 to $2 \mathrm{~d}$ before the trial were occluded. Each opening was dried by wiping with absorbent paper and then sealed with cyanoacrylate glue (Aron Alpha, Toa Gosei). The glue became hard immediately. This treatment was done $1.5 \mathrm{~h}$ prior to the trial. The blocks were checked immediately before and after each trial. At the end of each experiment, the sealed operculum was freed using glue remover (Toa Gosei). Another 10 postmolt females underwent a control operation. They were subjected to the same physical handling stress associated with the sealing operation, except that the glue was put on the carapace beside the opening. Male crabs were transferred to test tanks $(16 \times 26 \times 16 \mathrm{~cm})$ and acclimated individually for $1 \mathrm{~h}$ at ambient temperature, and then a female crab was put in the test tank. The grasping and copulation behaviors of male crabs towards females were observed for $1 \mathrm{~h}$.

Similarly, the gonopore, anus, and edge of abdominal flap of 5 postmolt females that had molted 1 to $2 \mathrm{~d}$ before were occluded. Each gonopore, anus, and the edge of abdominal flap was dried by wiping with absorbent paper and sealed with cyanoacrylate glue (Aron Alpha). The glue became hard immediately. This treatment was done $24 \mathrm{~h}$ prior to the trials. The blocks were checked immediately before and after each trial. Another 5 postmolt females underwent a control operation. They were subjected to the same physical handling stress associated with the sealing operation, except that the glue was put on the abdomen besides the flap. Male crabs were transferred to test tanks $(31.5 \times 18.5 \times 24.4 \mathrm{~cm})$ and acclimated individually for $1 \mathrm{~h}$ at ambient temperature, and then female crabs were placed in the test tank. The grasping and copulation behaviors of male crabs towards females were observed for $1 \mathrm{~h}$. Results were evaluated statistically using the Fisher exact test (Zar 1999).

Is the copulation pheromone a contact pheromone? To examine whether the copulation pheromone is a contact pheromone or not, we first scrubbed the body surface of postmolt females with sponges which were then given to male crabs. The entire body surface and limbs of a female, which had molted $1 \mathrm{~d}$ before, were scrubbed, and 20 sponges were prepared from 20 females (scrubbed). Of these 20 sponges, 10 had $20 \mu$ of postmolt female urine added, which is known to be enough to elicit grasping behavior in the male (Kamio et al. 2000; scrubbed/urine). Male responses were observed as in the sponge assay described above. Differences in male responses between the 2 treatment groups were evaluated by the Fisher exact test (Zar 1999).
To clarify whether the pheromone is released from the body surface or not, responses of males toward freezefixed females were observed. Ten females (live) that elicited copulation behavior of male crabs were freezefixed by freezing at $-20{ }^{\circ} \mathrm{C}$ and stored until required. They were thawed in seawater at ambient temperature for $2 \mathrm{~h}$ prior to experiments. Male crabs which had been transferred to test tanks $(31.5 \times 18.5 \times 24.4 \mathrm{~cm})$ and acclimated for $1 \mathrm{~h}$ at ambient temperature were placed closed to the treated female crabs (freeze-fixed). The grasping and copulation behaviors of male crabs towards females were observed for $1 \mathrm{~h}$. Differences in male responses between the 2 treatment groups were evaluated by the Fisher exact test (Zar 1999).

\section{RESULTS}

\section{Stimulus released from postmolt females that elicit copulation behavior of male crabs}

Responses of male crabs toward SW-dipped, predipped, post-dipped, pre-maintained and post-maintained sponges are summarized in Fig. 3. Thirty-nine out of 41 males grasped the post-maintained sponges, of which 25 copulated with the sponges. Similarly, 18 out of 34 males grasped the post-dipped sponges, of which 5 copulated with them. On the other hand, 14 out of 28, and 18 out of 29 males grasped pre-dipped and pre-maintained sponges, respectively. However, conversely, none of the crabs of these 2 groups copulated with the sponges. Only 1 of 29 males grasped SW-dipped (control) sponges and none copulated.

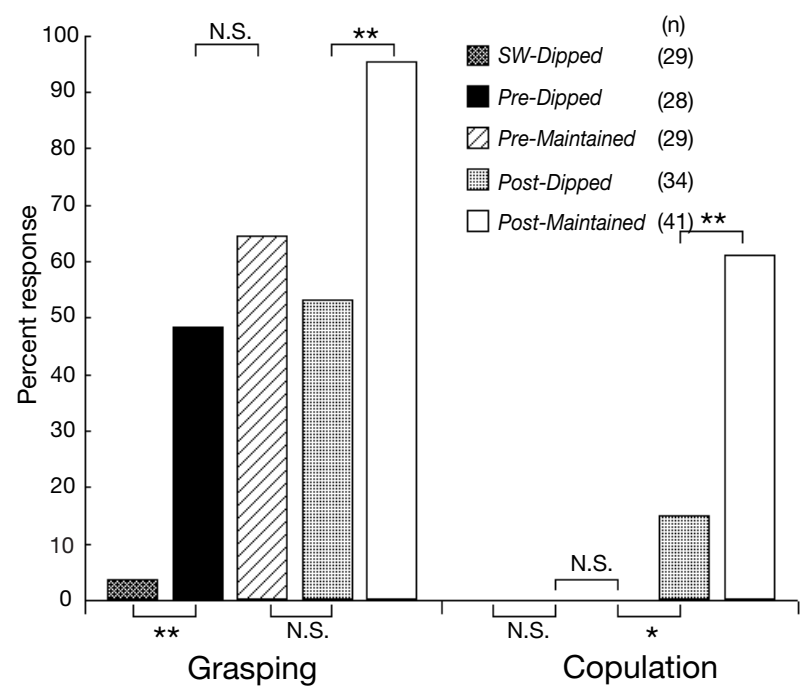

Fig. 3. Telmessus cheiragonus. Response of male crabs to urethane sponges conditioned with aquarium water of pre- and postmolt females. $* \star p<0.01 ; * \mathrm{p}<0.05$, respectively; N.S.: not significant 
Differences in grasping behavior between control (SW-dipped) and all experimental groups were significant (Fisher exact test, $\mathrm{p}<0.01$ ). Those between postmaintained and the other 3 experimental groups were significant (Fisher exact test, $\mathrm{p}<0.01$ ). Copulation behaviors were observed in only 2 experimental conditions (post-dipped and post-maintained). The difference between the male crabs' responses to these 2 conditions was significant (Fisher exact test, $\mathrm{p}<0.01$ ).

\section{Molecular size of the copulation pheromone}

Responses of male crabs toward SW, glass filtrate, $10 \mathrm{kDa}$, and $1 \mathrm{kDa}$ filtrate sponges are summarized in Fig. 4. Fifteen out of 30 males grasped the $10 \mathrm{kDa}$ filtrate sponges, of which 5 males copulated with the sponges. Similarly, 16 of 30 males grasped the $1 \mathrm{kDa}$ filtrate sponges, of which 3 copulated with them. Eighteen of 30 males grasped the glass filtrate sponges and 4 of them copulated with the sponges. Only 1 of 20 males grasped the SW sponges and none copulated.

Differences between the control (SW) and all experimental groups were significant in grasping behavior (Fisher exact test, $\mathrm{p}<0.01$ ), whereas no significant difference was observed between the filtrate groups (Fisher exact test, $\mathrm{p}>0.05$ ). Copulation behaviors were observed only for glass filtrate, $10 \mathrm{kDa}$ and $1 \mathrm{kDa}$ filtrate sponges, although the differences between control and filtrate groups were not significant.

\section{Duration of the pheromone release}

Males grasped and copulated with sponges conditioned with females that had molted 2 to $21 \mathrm{~d}$ before

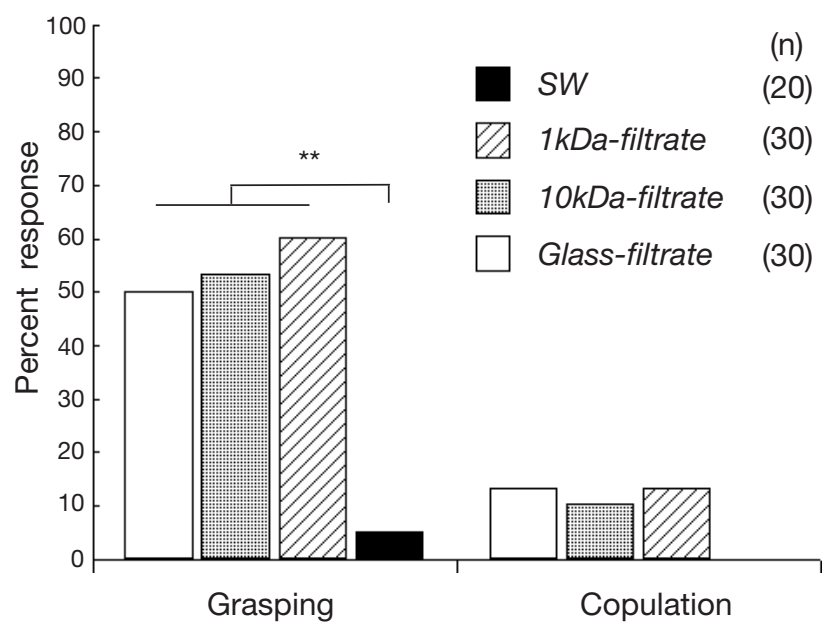

Fig. 4. Telmessus cheiragonus. Response of male crabs to urethane sponges containing filtrates obtained by ultrafiltration. $\star * \mathrm{p}<0.01$ the assays (Fig. 5). In the experiment with hard females that had molted $22 \mathrm{~d}$ before, 18 out of 20 males tried to grasp the females and struggled with her. Although 4 of the 18 males placed females into the copulatory position, insertion of gonopods was unsuccessful due to the resistance of females.

\section{Location of the release site of the copulation pheromone}

Sponges containing postmolt female urine (postmolt urine) induced grasping behavior in 30 out of 40 males, but no copulation was observed. On the other hand, 35 of 49 males grasped the sponges containing water conditioned with postmolt females (postmolt water) and 11 males copulated with the sponges (Fig. 6).

The difference in grasping behavior was not significant (Fisher exact test, p > 0.05), but the difference between copulation-inducing activity of the postmolt water sponge was significantly higher than the postmolt urine sponges (Fisher exact test, $\mathrm{p}<0.01$; Fig. 6).

In the experiment of male responses toward females that were prevented from urine release, all 10 males grasped and copulated with both occluded and control females, respectively. The difference between the 2 groups was not significant (Fisher exact test, $\mathrm{p}=1$ ). Similarly, postmolt females whose gonopore, anus and abdominal flap were sealed elicited grasping and copulation behaviors in all 5 males. The difference between the 2 groups was not significant (Fisher exact test, $\mathrm{p}=1$ ).

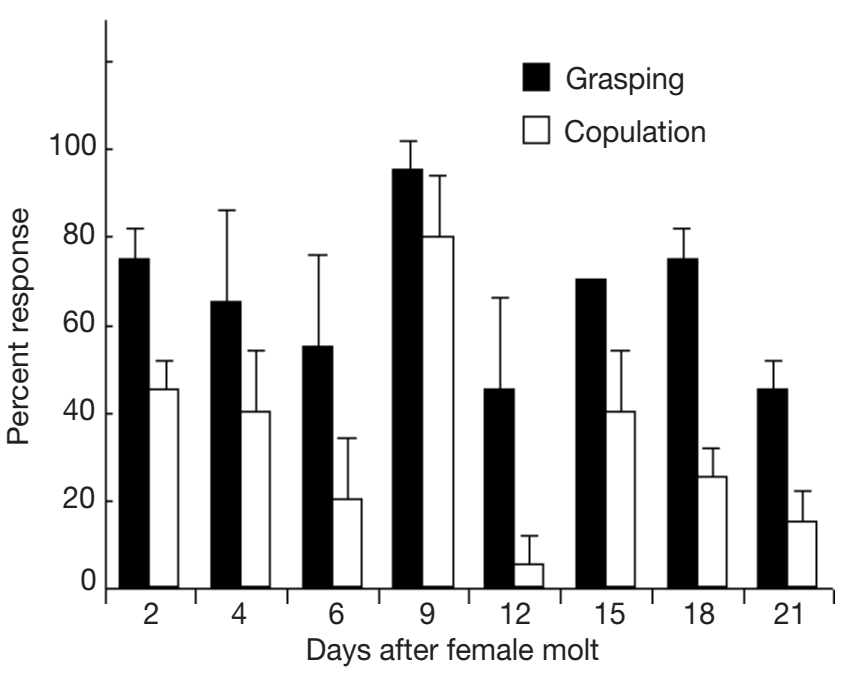

Fig. 5. Telmessus cheiragonus. Grasping and copulation behaviors of male crabs toward the urethane sponges conditioned with females of various postmolt periods. Values are means $\pm \mathrm{SD}$ 


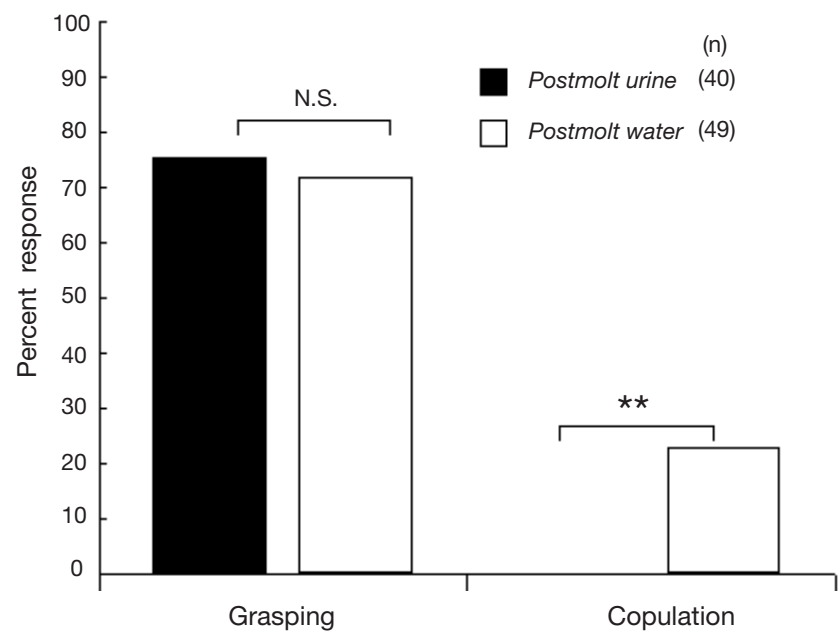

Fig. 6. Telmessus cheiragonus. Response of male crabs to urethane sponges conditioned with urine and aquarium water of postmolt females. $* \star p<0.01$; N.S.: not significant

\section{Copulation pheromone is not a contact pheromone}

Scrubbed and scrubbed/urine sponges induced grasping behavior in 7 out of 10 males, but no copulation was observed. In contrast, all 10 males tested grasped the postmolt water sponges, of which 5 males copulated with the sponges (Fig. 7).

The grasping-behavior-inducing activity was not significant between scrubbed and postmolt water sponges (Fisher exact test, $\mathrm{p}>0.05$ ), whereas the copulation-inducing activity of the latter was significantly higher than that of the former (Fisher exact test, $\mathrm{p}<$ 0.05; Fig. 7).

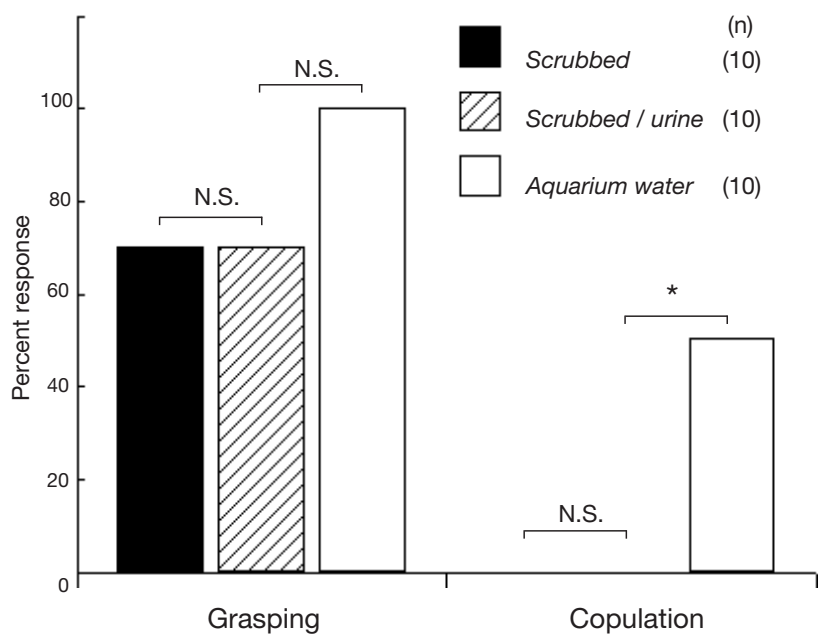

Fig. 7. Telmessus cheiragonus. Response of male crabs to urethane sponges scrubbed with the body surface of postmolt females, scrubbed sponges containing $20 \mu \mathrm{l}$ postmolt female urine, and sponges containing aquarium water of postmolt females. $* \mathrm{p}<0.05$; N.S.: not significant

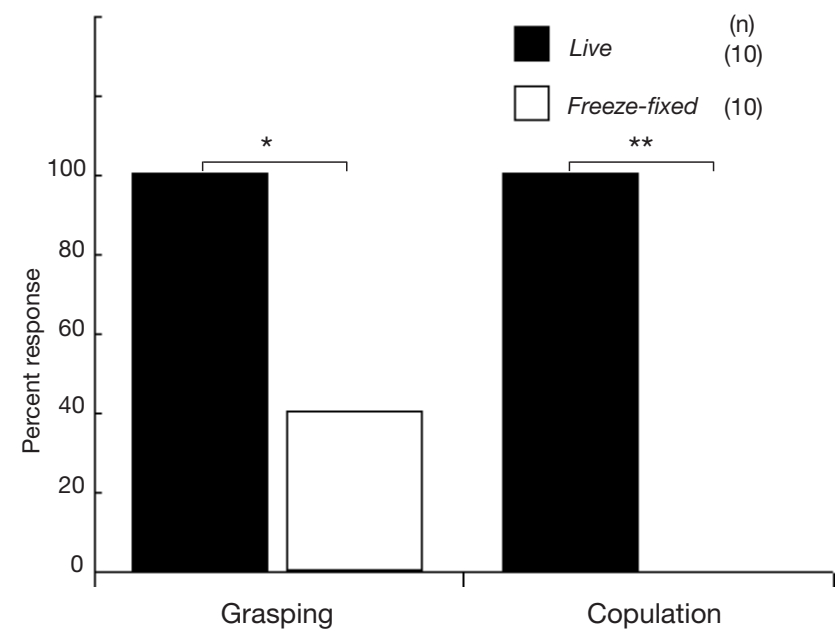

Fig. 8. Telmessus cheiragonus. Response of male crabs to live and freeze-fixed postmolt females. $* \star p<0.01 ; * \mathrm{p}<0.05$

On the other hand, 4 out of 10 males grasped freezefixed postmolt females, but no copulation was observed (Fig. 8). Incidentally, all 10 males grasped and copulated with live postmolt females. The grasping and copulation behavior-inducing activity of live females was significantly higher than that of the freeze-fixed females (Fisher exact test, p $<0.05$ and $\mathrm{p}<0.01$, respectively)

\section{DISCUSSION}

In brachyuran crustaceans, signals that elicit precopulatory behaviors, including mate location, courtship display and precopulatory mate guarding, have been reported (Dunham 1978, Gleeson 1980, Salmon 1983, Bushman 1999). The signals eliciting copulation behaviors have, however, received less attention. Our behavioral assay provides the first definitive evidence for the presence of a copulation pheromone in Brachyura. To our knowledge, this is the first report for any Crustacea that suggests that copulation behavior is elicited by a pheromone released from the female. Our sponge assay excludes the possibility that other stimuli such as visual and acoustic cues from female crabs might be responsible for evoking the copulation response in males in the experiments.

The experiments using the sponges conditioned with premolt and postmolt females demonstrated the existence of a pheromone eliciting male copulatory behavior released from postmolt females (Fig. 3). The chemical signal released from premolt females evoked only grasping behavior. This is consistent with the observation by Asai (1996) who reported that Telmessus cheiragonus males only copulate with postmolt females, 
while the males initiate mate guarding with premolt females. Thus, the grasping and copulation behaviors of male crabs were elicited by distinct pheromones released from pre- and postmolt females, respectively.

Post-dipped sponges that had had no contact with females' body elicited copulation behavior in males. This means that the copulation pheromone is a water-borne pheromone. Furthermore, the molecular size of the pheromone is less than $1 \mathrm{kDa}$ as suggested by the ultrafiltration experiment (Fig. 4). The copulation and grasping behaviors of males were more potently evoked by post-maintained sponges than by post-dipped sponges (Fig. 3). Post-maintained sponges might have had contact with postmolt females, whereas post-dipped sponges had no female contact. Since post-maintained sponges had been immersed in the water longer than post-dipped sponges, it is possible that the longer immersion period resulted in absorption of larger amounts of the pheromone. However, the possibility remains that an additional factor was adsorbed onto the sponges due to contact with the crabs. The contact pheromone in mate recognition was predicted in the shore crab Carcinus maenas (Bamber \& Naylor 1996b).

The antennal gland openings were not the release site of the copulation pheromone. Postmolt female urine did not elicit male copulation behavior (Fig. 6). Similarly, inhibition of urine release from female crabs did not affect male copulation behavior. Thus, urine release is not necessary to evoke copulation behavior in male crabs.

Copulation pheromones of gammarid amphipods (Borowsky 1991) are predicted to be contact pheromones which are secreted through pore canals that are distributed all over the female exoskeleton; such pore canals have been described by Halcrow (1978). Male crabs may perceive this pheromone during palpation through chemoreceptors located on their limbs. Palpation involves repeated contact by males with the exoskeleton of the other individuals using second antennae, chelae, mouth parts and walking limbs (Borowsky \& Borowsky 1991). Palpation behavior was also reported for the helmet crab where it was referred to as 'fumbled' behavior by Asai 1996. We initially thought that the copulation pheromone was a contact pheromone present on the body surface of postmolt females. However, the sponges which had scrubbed the body surface of postmolt females did not elicit copulation behavior in males (Fig. 7), and males did not copulate with freeze-fixed postmolt females (Fig. 8). Since the pheromone is stable under freezing and thawing conditions (Figs. 4, $6 \&$ 7), it is apparent that the copulation pheromone does not exist on the body surface of postmolt females. It is likely that postmolt females control the release of the pheromone. The experiments with postmolt females whose gonopore, anus, and abdominal flap were sealed showed that the pheromone is released from other sites.

In the experiment summarized in Fig. 3, sperm plugs deposited on 11 sponges were observed (Fig. 1B). This indicates that males were stimulated enough to release their sperm into the sponges. If this pheromone elicits copulation behavior in males even when distant from the source of release, then males will copulate with 'non-proper objects' as they did in the present study with the sponges. Hence, release of this pheromone must be controlled properly by female crabs. In some terrestrial animals, attractants are air-borne, whereas copulation pheromones work as contact pheromones (Soneshine 1985, Agosta 1992, Fauziah et al. 1992). The contact nature may act as a safety lock which prevents eliciting copulation in individuals at a long distance.

From preliminary laboratory observations, the copulation of Telmessus cheiragonus was seen to occur within some minutes to hours after the molt when females were soft. However, the copulation pheromone was still released $21 \mathrm{~d}$ after the molt. This period is longer than 'real copulation timing' but coincides with the report that grasping-behavior-inducing pheromone was released in female urine at least $2 \mathrm{wk}$ after ecdysis and after copulation (Kamio et al. 2000). Thus, the grasping-behavior-inducing pheromone and copulation-inducing pheromone were still released when female crab carapaces were hard. However, females with hard carapaces that were still releasing the pheromone $22 \mathrm{~d}$ after the molt, resisted the males and copulation did not occur. Therefore, both release of copulation pheromone and passive behavior of the females are required for successful copulation. The postmolt females used in our experiments had not copulated before. Duration of the pheromone release from copulated females remains to be tested.

No crustacean sex pheromone has been fully elucidated; partial characterizations of a few pheromones have been so far reported. The sex pheromone released in female urine of the blue crab Callinectes sapidus had a molecular weight of between 300 and $600 \mathrm{Da}$ and was stable under heating and freezingthawing conditions (Gleeson 1991). The sex pheromone released from females of the American lobster Homarus americanus was also water-borne and stable after freezing and assumed to be a multi-component pheromone (McLeese et al. 1977) as reported in many insects (Chapman 1998). Chemotactile pheromones of copepods are believed to be glycoproteins present on the body surface of females (Snell \& Carmona 1994, Lonsdale et.al. 1996, Kelly \& Snell 1998). The copulation pheromone of Telmessus cheiragonus appeared to have a molecular weight of less than $1 \mathrm{kDa}$ and is stable after freezing-thawing treatment. 
In this study, we demonstrated that the precopulatory behavior and copulation behavior of sexually competent male crabs are evoked by different chemical stimuli released from pre- and postmolt females. There are still many problems to be solved; most importantly, the characterization of the chemical nature of the pheromone is essential for further insight into mating behaviors of the crabs.

Acknowledgements. We are indebted to the staff of the Usujili Fisheries Laboratory, Japan, for their help and allowing us to use their facilities. We also thank Dr. Jiro Nagao, Ehime University, Japan, for valuable discussion. This study was supported by a research fund from the Nissan Science Foundation, and a Research Fellowship from the Japan Society for Promotion of Science for Young Scientists to M.K. is acknowledged.

\section{LITERATURE CITED}

Agosta WC (1992) Chemical communication: the language of pheromones. WH Freeman, New York

Asai N (1996) Studies on sex pheromone of hair crabs. PhD thesis, University of Tokyo

Bamber SD, Naylor E (1996a) Chemical communication and behavioral interaction between sexually mature male and female shore crabs (Carcinus maenus). J Mar Biol Assoc UK 76:691-699

Bamber SD, Naylor E (1996b) Mating behaviour of male Carcinus maenus in relation to a putative sex pheromone: behavioural changes in response to antennule restriction. Mar Biol 125:483-488

Bamber SD, Naylor E (1997) Sites of release of putative sex pheromone and sexual behavior in female Carcinus maenus (Crustacea: Decapoda). Estuar Coast Shelf Sci 44:195-202

Borowsky B (1991) Patterns of reproduction of some amphipod crustaceans and insights into the nature of their stimuli. In: Martin JW, Bauer RT (eds) Crustacean sexual biology. Columbia University Press, New York, p 33-49

Borowsky B, Borowsky R (1991) The reproductive behaviors of the amphipod crustacean Gammarus palustris (Bousfield) and some insights into the nature of their stimuli. J Exp Mar Biol Ecol 107:131-144

Bushmann PJ (1999) Concurrent signals and behavioral plasticity in blue crab (Callinectes sapidus Rathbun) courtship. Biol Bull 197:63-71

Chapman RF (1998) The insects: structure and function, 4th edn. Cambridge University Press, Cambridge

Dunham PJ (1978) Sex pheromone in Crustacea. Biol Rev 53:555-583

Editorial responsibility: Joseph Pawlik (Contributing Editor), Wilmington, North Carolina, USA
Eales AJ (1974) Sex pheromone in the shore crab Carcinus maenas, and the site of its release from females. Mar Behav Physiol 12:345-355

Fauziah BA, Tabata K, Ito K, Takahashi S, Hidaka T (1992) Mating behavior of the cryptomeria bark borer, Semanotus japonicus Lacordaire (Coleoptera: Cerambycidae). Appl Entomol Zool 27:19-30

Gleeson RA (1980) Pheromone communication in the reproductive behavior of the blue crab, Callinectes sapidus. Mar Behav Physiol 7:119-134

Gleeson RA (1991) Intrinsic factors mediating pheromone communication in the blue crab, Callinectes sapidus. In: Martin JW, Bauer RT (eds) Crustacean sexual biology. Columbia University Press, New York, p17-32

Halcrow K (1978) Modified pore canals in the cuticle of Gammarus (Crustacea: Amphipoda); a study by electron scanning and transmission electron microscopy. Tissue Cell 10:659-670

Hardege JD (1999) Nereidid polychaetes as a model organisms for marine chemical ecology. Hydrobiologia 402: 145-161

Hartnoll RG (1969) Mating in Brachyura. Crustaceana 16: 161-181

Kamio M, Matsunaga S, Fusetani N (2000) Studies on sex pheromones of the helmet crab, Telmessus cheiragonus 1. An assay based on precopulatory mate-guarding. Zool Sci 17:731-733

Kelly LS, Snell TW (1998) Roles of surface glycoproteins in mate-guarding of the marine harpacticoid Tigriopus japonics. Mar Biol 130:605-612

Lonsdale DJ, Snell TW, Frey MA (1996) Lectin binding to surface glycoproteins on Coullana spp. (Copepoda: Harpacticoida). Mar Behav Physiol 27:153-162

McLeese DW, Spraggins RL, Bose AK, Pramanik BN (1977) Chemical and behavioral studies of the sex attractant of the lobster (Homarus americanus). Mar Behav Physiol: 4: $219-232$

Nagao J (1999) Studies on the growth and the reproduction of the helmet crab, Telmessus cheiragonus. PhD thesis, Hokkaido University, Hakodate

Ryan EP (1966) Pheromone: evidence in a decapod crustacean. Science 151:340-341

Salmon M (1983) Courtship, mating systems and sexual selection in Decapods. In: Rebach S, Dunham DW (eds) Studies in adaptation; the behavior of higher Crustacea. WileyLiss, New York, p 143-169

Snell TW, Carmona MJ (1994) Surface glycoproteins in copepods: potential signal for mate recognition. Hydrobiologia 292/293:255-264

Sonenshine RP (1985) Pheromones and other semio chemicals of the Acari. Annu Rev Entomol 30:1-28

Zar JH (1999) Biostatistical analysis, 4th edn. Prentice-Hall, Upper Saddle River, NJ

Submitted: February 6, 2001; Accepted: November 16, 2001

Proofs received from author(s): May 2, 2002 